\title{
Accumulation of the Authentic Parkin Substrate Aminoacyl- tRNA Synthetase Cofactor, p38/JTV-1, Leads to Catecholaminergic Cell Death
}

\author{
Han Seok Ko, ${ }^{1,2}$ Rainer von Coelln, ${ }^{1,2}$ Sathya R. Sriram, ${ }^{1,2,6}$ Seong Who Kim, ${ }^{1,2}$ Kenny K. K. Chung, ${ }^{1,2}$ Olga Pletnikova, \\ Juan Troncoso, ${ }^{2,5}$ Brett Johnson, ${ }^{1,2}$ Roya Saffary, ${ }^{1,2}$ Eyleen L. Goh, ${ }^{1,2}$ Hongjun Song, ${ }^{1,2,3,6}$ Bum-Joon Park, ${ }^{7}$ \\ Min Jung Kim, ${ }^{7}$ Sunghoon Kim, ${ }^{7}$ Valina L. Dawson, ${ }^{1,2,3,4,6}$ and Ted M. Dawson ${ }^{1,2,3,6}$ \\ ${ }^{1}$ Institute for Cell Engineering, Departments of ${ }^{2}$ Neurology, ${ }^{3}$ Neuroscience, ${ }^{4}$ Physiology, and ${ }^{5}$ Pathology, and ${ }^{6}$ Graduate Program in Cellular and Molecular \\ Medicine, Johns Hopkins University School of Medicine, Baltimore, Maryland 21205, and ${ }^{7}$ National Creative Research Initiatives Center for Human \\ Aminoacyl-tRNA Synthetases Network, College of Pharmacy, Seoul National University, Seoul 151-742, Korea
}

\begin{abstract}
Autosomal-recessive juvenile parkinsonism (AR-JP) is caused by loss-of-function mutations of the parkin gene. Parkin, a RING-type E3 ubiquitin ligase, is responsible for the ubiquitination and degradation of substrate proteins that are important in the survival of dopamine neurons in Parkinson's disease (PD). Accordingly, the abnormal accumulation of neurotoxic parkin substrates attributable to loss of parkin function may be the cause of neurodegeneration in parkin-related parkinsonism. We evaluated the known parkin substrates identified to date in parkin null mice to determine whether the absence of parkin results in accumulation of these substrates. Here we show that only the aminoacyl-tRNA synthetase cofactor p38 is upregulated in the ventral midbrain/hindbrain of both young and old parkin null mice. Consistent with upregulation in parkin knock-out mice, brains of AR-JP and idiopathic PD and diffuse Lewy body disease also exhibit increased level of p38. In addition, p38 interacts with parkin and parkin ubiquitinates and targets p38 for degradation. Furthermore, overexpression of p38 induces cell death that increases with tumor necrosis factor- $\alpha$ treatment and parkin blocks the pro-cell death effect of $\mathrm{p} 38$, whereas the R42P, familial-linked mutant of parkin, fails to rescue cell death. We further show that adenovirus-mediated overexpression of $\mathrm{p} 38$ in the substantia nigra in mice leads to loss of dopaminergic neurons. Together, our study represents a major advance in our understanding of parkin function, because it clearly identifies p38 as an important authentic pathophysiologic substrate of parkin. Moreover, these results have important implications for understanding the molecular mechanisms of neurodegeneration in PD.
\end{abstract}

Key words: Parkinson's disease; parkin; ubiquitination; proteasome degradation; p38/JTV1; dopaminergic neuronal cell death

\section{Introduction}

Parkinson's disease (PD) is one of the most common neurodegenerative disorders characterized by the progressive and selective loss of dopaminergic neurons in the substantia nigra pars compacta $(\mathrm{SNpc})$ and the presence of intracellular inclusions, named Lewy bodies (Dawson and Dawson, 2003). Deficiency of these neurons causes progressive motor impairments, including tremor, rigidity, and bradykinesia. Although the majority of PD is sporadic, the identification of familial PD-linked mutations in

Received May 28, 2005; revised July 12, 2005; accepted July 14, 2005.

This work was supported by National Institutes of Health-National Institute of Neurological Disorders and Stroke Grants NS 38377 and NS 48206, the Lee Martin Trust, the Sylvia Nachlas Trust, a grant from the National Creative Research Initiatives of the Ministry of Science and Technology, Korea, and Korea Research Foundation Grant KRF2004-037-E00002. T.M.D. is the Leonard and Madlyn Abramson Professor in Neurodegenerative Diseases. We thank Yoshikuni Mizuno for the gift of AR-JP and control brains and Simone Engelender for the gift of the synphilin-1 antibody.

Correspondence should be addressed to Dr. Ted M. Dawson, Institute for Cell Engineering, Johns Hopkins University School of Medicine, 733 North Broadway Street, Suite 731, Baltimore, MD 21205. E-mail: tdawson@jhmi.edu.

M. J. Kim's present address: Department of Genetics and Development, Columbia University Medical Center, New York, NY 10032.

DOI:10.1523/JNEUROSCI.2172-05.2005

Copyright $\odot 2005$ Society for Neuroscience $\quad 0270-6474 / 05 / 257968-11 \$ 15.00 / 0$ genes encoding $\alpha$-synuclein (Polymeropoulos et al., 1997), DJ-1 (Bonifati et al., 2003), PINK-1 (Valente et al., 2004), LRRK2 (Paisan-Ruiz et al., 2004; Zimprich et al., 2004), and parkin (Kitada et al., 1998) has provided tremendous insight into the pathogenesis of PD (Cookson, 2005). The finding that parkin is an ubiquitin E3 ligase provided an important link between protein aggregation and the ubiquitin-proteasome system (UPS) in the pathogenesis of PD (Shimura et al., 2000; Zhang et al., 2000). Mutations in parkin appear to be very prevalent and account for up to $50 \%$ of familial PD (von Coelln et al., 2004a). Parkin is an E3 ligase that is responsible for the addition of poly-ubiquitin chains on specific substrates (von Coelln et al., 2004a), which is recognized by the proteasome for degradation (Sakata et al., 2003). It is thought that autosomal-recessive juvenile parkinsonism (AR-JP)-linked parkin mutants lead to a loss of the ubiquitin ligase activity of parkin and thus fail to ubiquitinate parkin substrates, leading to their accumulation (Cookson, 2003). Accumulation of one or more of the putative substrates of parkin is ultimately thought to be toxic to catecholaminergic neurons (Dong et al., 2003). Identification of authentic substrates has important implications for not only AR-JP but also sporadic PD because 
parkin is $S$-nitrosylated in idiopathic PD. S-nitrosylation of parkin inhibits its ubiquitination and protective function (Chung et al., 2004; Yao et al., 2004); thus, accumulation of parkin substrates may also contribute to the neurodegeneration in sporadic PD. A number of parkin substrates have been identified including, CDCrel-1, CDCrel-2, synphilin-1, glycosylated $\alpha$-synuclein, $\beta$-tubulin, cyclin E, synaptotamin XI (SytXI), parkin-associated endothelin-like receptor (Pael-R), and p38/JTV-1 subunit of the multi-tRNA synthetase complex (Zhang et al., 2000; Chung et al., 2001; Imai et al., 2001; Shimura et al., 2001; Choi et al., 2003; Corti et al., 2003; Huynh et al., 2003; Ren et al., 2003; Staropoli et al., 2003; Jiang et al., 2004). CDCrel-1, CDCrel-2, Pael-R, and cyclin E appear to be upregulated in AR-JP brains (Imai et al., 2001; Choi et al., 2003; Staropoli et al., 2003), but none of these substrates have been reported to be upregulated in parkin knockout $(\mathrm{KO})$ mice. Parkin-deficient mice with targeted disruption of parkin exon 3, which have subtle behavioral deficits and enhanced dopamine metabolism without loss of dopaminergic neurons (Goldberg et al., 2003; Itier et al., 2003), surprisingly, showed similar levels of CDCrel-1, synphilin-1, and $\alpha$-synuclein (Goldberg et al., 2003; Palacino et al., 2004). Moreover, there seems to be reductions in mitochondrial-associated proteins in parkin exon 3-deleted mice, which leads to potential mitochondrial defects (Palacino et al., 2004). We recently reported that targeted disruption of parkin exon 7 creates a parkin null phenotype that leads to a reduced number of locus ceruleus neurons, deficits of norepinephrine in the olfactory bulb and spinal cord, and a marked reduction of the norepinephrine-modulated startle response (von Coelln et al., 2004b). We analyzed the levels of known parkin substrates in the brains of parkin exon 7 null mice and AR-JP patients, and here we report the discovery that p38/ JTV-1 accumulates in parkin exon 7 null mice and AR-JP brains. Moreover, it accumulates in sporadic PD brains, and adenoviral (AV)-mediated overexpression of p38 leads to selective DA neuronal cell death.

\section{Materials and Methods}

cDNA, cell culture, and antibodies. Full-length human p38 cDNA was cloned into the mammalian expression vector pCMV-2A-FLAG (Stratagene, La Jolla, CA). Expression plasmids for FLAG-tagged human parkin and V5-tagged human heat shock protein 70 (Hsp70) were kindly provided by R. Takahashi (RIKEN Brain Science Institute, Tokyo, Japan), and hemagglutinin (HA)-tagged mouse C-terminus of hsc70interacting protein (CHIP) was kindly provided by S. Hatakeyama (Kyushu University, Fukuoka-shi, Japan). Human full-length parkin and its deletion mutants and ubiquitin cDNAs were cloned into pRK5-HA vector as described previously (Chung et al., 2001). A plasmid containing $\beta$-galactosidase cDNA was used as a control in all experiments. The integrity of all constructs was confirmed by sequencing.

Human neuroblastoma SK-N-MC and SH-SY5Y cells were purchased from American Type Culture Collection (Manassas, VA). They were maintained in modified Eagle's medium and DMEM supplemented with $10 \%(\mathrm{v} / \mathrm{v})$ heat-inactivated fetal calf serum at $37^{\circ} \mathrm{C}$ in a humidified $5 \%$ $\mathrm{CO}_{2} / 95 \%$ air atmosphere, respectively. Human neuroblastoma SK$\mathrm{N}-\mathrm{MC}$ and SH-SY5Y cells were transiently transfected with the target vector by the Lipofectamine method according to the instructions of the manufacturers (Invitrogen, Carlsbad, CA).

Adult neural stem cells were isolated from the brains of adult parkin null mice and their littermates and cultured as described previously (Zhao et al., 2003).

To prepare the stable transformed cells, SH-SY5Y cells were transfected with pcDNA3-HA-p38. Selections were started $2 \mathrm{~d}$ later using a medium containing $700 \mu \mathrm{g} / \mathrm{ml}$ geneticin (Invitrogen). Individual clones were isolated, and their characterization was examined by Western blotting with an antibody against anti-HA.
To generate a peptide antigen of $\mathrm{p} 38$, a peptide containing the last 18 amino acids of the $\mathrm{C}$ terminal of $\mathrm{p} 38$ was synthesized and cross-linked to keyhole limpet hemocyanin. The conjugated peptide was then used to immunize a New Zealand white rabbit (JH745-748) (Cocalico Biologicals, Reamstown, PA). Antisera were purified by affinity chromatography using the same peptide immobilized on SulfoLink gel matrix (Pierce, Rockford, IL) according to the protocol of the manufacturer. Antibody specificity was confirmed by the ability to preabsorb the immunostaining with excess purified p38 protein and with p38 knock-out mice. p38 monoclonal antibody was kindly provided by S. Kim (University of Seoul, Seoul, Korea), and Pael-R monoclonal antibody was kindly provided by R. Takahashi (RIKEN Brain Science Institute, Tokyo, Japan).

In vitro pull-down assay and immunoprecipitation. The p38 cDNA was cloned into the pGEX-KT vector (Amersham Biosciences, Piscataway, $\mathrm{NJ}$ ) to produce the fusion protein glutathione $S$-transferase (GST)-p38. Expression and purification of GST-p38 and GST alone (as a control) using glutathione-Sepharose 4B (Amersham Biosciences) was performed as recommended by the manufacturer. In vitro translation of parkin wild-type (WT) and 77-465 were performed with rabbit reticulocyte lysate (Promega, Madison, WI) and ${ }^{35} \mathrm{~S}$-methionine according to instructions of the manufacturer. The glutathione-Sepharose beads with bound GST-fusion proteins and in vitro-translated parkin WT and 77465 were incubated in bead-binding buffer [ $50 \mathrm{~mm} \mathrm{~K}$-phosphate, $\mathrm{pH} 7.5$, $100 \mathrm{~mm} \mathrm{KCl}$, and $10 \%$ glycerol (v/v) $/ 0.1 \%$ Triton X-100] at $4^{\circ} \mathrm{C}$ for $2 \mathrm{~h}$. The beads were washed four times with bead-binding buffer without glycerol and Triton X-100. Beads were then heated for $5 \mathrm{~min}$ at $95^{\circ} \mathrm{C}$ in SDS-sample buffer and analyzed by SDS-PAGE. Bands were visualized by autoradiography.

For coimmunoprecipitation from cell cultures, SH-SY5Y cells were transfected with $2 \mu \mathrm{g}$ of each plasmid. After $48 \mathrm{~h}$, cells were washed with cold PBS and harvested in immunoprecipitation buffer (1\% Triton $\mathrm{X}-100,2 \mu \mathrm{g} / \mathrm{ml}$ aprotinin, and $100 \mu \mathrm{g} / \mathrm{ml}$ PMSF in PBS). The lysate was then rotated at $4^{\circ} \mathrm{C}$ for $1 \mathrm{~h}$, followed by centrifugation at $14,000 \mathrm{rpm}$ for $20 \mathrm{~min}$. The supernatants were then combined with $50 \mu$ lof protein $\mathrm{G}$ Sepharose (Amersham Biosciences) preincubated with antibodies against HA or myc (Roche, Indianapolis, IN), followed by rotating at $4^{\circ} \mathrm{C}$ for $2 \mathrm{~h}$. The protein G Sepharose was pelleted and washed three times using immunoprecipitation buffer or buffer with additional $500 \mathrm{~mm}$ $\mathrm{NaCl}$, followed by three washes with PBS. The precipitates were resolved on SDS-PAGE gel and subjected to Western blot analysis. Immunoblot signals were visualized with enhanced chemiluminescence (Amersham Biosciences).

For coimmunoprecipitation of the endogenous proteins from human brain, frontal cortex gray matter was homogenized in 4 vol of ice-cold PBS containing $320 \mathrm{~mm}$ sucrose and $0.1 \%$ Triton X-100 with protease inhibitor cocktail (Sigma, St. Louis, MO). The tissue homogenate was centrifuged at $37,000 \times g$ at $4^{\circ} \mathrm{C}$ for $20 \mathrm{~min}$. The supernatant was used for immunoprecipitation with one of the following antibodies: anti-HA (Roche), anti-myc (Roche), anti-p38, or anti-parkin. Immunoprecipitates were separated by SDS-PAGE and subjected to Western blot analysis with an anti-p38 monoclonal antibody. Immunoblot signals were visualized with enhanced chemiluminescence (Amersham Biosciences). For mapping of the binding region between parkin and p38, the myctagged parkin deletion constructs were generated as described previously (Chung et al., 2001), and the myc-tagged p38 deletion fragments were generated as described previously (Kim et al., 2003). We transfected each of the plasmids encoding the deletion fragments of parkin and p38 into SH-SY5Y cells. p38 and parkin were precipitated with the anti-HA antibody (Roche), and the coprecipitation of their counterparts was determined by Western blotting with the corresponding antibodies. Detection was performed with enhanced chemiluminescence (Amersham Biosciences).

In vivo ubiquitination assay. For in vivo ubiquitination assay from cell cultures, SH-SY5Y cells were transiently transfected with $2 \mu \mathrm{g}$ of pRK5myc-tagged parkin or myc-tagged parkin mutants, pCMV-FLAG-p38, and $2 \mu \mathrm{g}$ of pMT123-HA-ubiquitin plasmids for $24 \mathrm{~h}$ and then treated with the proteasome inhibitor MG132 (5 $\mu \mathrm{M})$ (Sigma) for $18 \mathrm{~h}$. Total cell lysates were prepared by harvesting the cells after washing with PBS, followed by solubilizing the pellets in $200 \mu \mathrm{l}$ of $2 \%$ SDS, followed by 
sonication. The lysates were then rotated at $4^{\circ} \mathrm{C}$ for $1 \mathrm{~h}$, diluted to $1 \mathrm{ml}$ with TBS, and then boiled and sonicated. A total of $50 \mu \mathrm{l}$ of the samples were used as input and for immunoprecipitation. Immunoprecipitation was performed with an antibody against FLAG. The precipitates were subjected to Western blotting with anti-HA or anti-FLAG antibodies.

Assessment of cell viability. To examine the effect of p38 on cell death, we cotransfected SK-N-MC cells with either control plasmid and HA tagged-p38 or HA tagged-p38 together with FLAG-parkin and HA tagged-p38 together with Arg42Pro parkin mutant and incubated for $24 \mathrm{~h}$, followed by treatment with tumor necrosis factor- $\alpha$ (TNF $\alpha)(\mathrm{PeP}-$ rotech, Rocky Hill, NJ) for $4 \mathrm{~h}$ in the presence of $10 \mu \mathrm{g} / \mathrm{ml}$ cycloheximide (Sigma) and monitored cell death by trypan blue staining.

Preparation of human and mouse brain tissue. Frontal cortical tissue from five control brains and eight PD and diffuse Lewy body (DLB) brains with high Lewy body burden that were age matched with similar postmortem intervals as described previously (Chung et al., 2004) were used to analyze parkin substrates in PD and DLB brains. In a separate cohort of brains frontal cortex tissue from four control brains and four AR-JP brains that were age matched with similar postmortem intervals as previously described (Moore et al., 2005) were used to compare parkin substrate levels in AR-JP brains. Parkin null mice were generated by Lexicon Genetics (The Woodlands, TX) as originally described (von Coelln et al., 2004b).

Detergent-soluble and -insoluble fractions were prepared from human brain tissue and mouse brain tissue by homogenization of samples in lysis buffer [10 mm Tris-HCl, pH 7.4, $150 \mathrm{~mm} \mathrm{NaCl}, 5$ mм EDTA, 0.5\% Nonidet P-40, 10 mm Na- $\beta$-glycerophosphate, Phosphate Inhibitor Mixture I and II (Sigma), and Complete Protease Inhibitor Mixture (Roche)], by using a Diax 900 homogenizer (Heidolph, Cinnaminson, $\mathrm{NJ})$. After homogenization, samples were rotated at $4^{\circ} \mathrm{C}$ for $30 \mathrm{~min}$ for complete lysis, then the homogenate was centrifuged $\left(10,000 \times g, 4^{\circ} \mathrm{C}, 20\right.$ $\mathrm{min}$ ), and the resulting pellet and supernatant fractions were collected. The pellet fractions was washed once in lysis buffer containing detergent, and the resulting pellet was solubilized in lysis buffer containing 1\% SDS. Fractions were quantitated using the BCA kit (Pierce) with BSA standards and analyzed by Western blot.

Western blotting was performed with an anti-parkin (PRK8 mouse monoclonal), anti-p38, anti-CDCrel-1 (Zhang et al., 2000), anti-Pael-R monoclonal antibody, anti- $\alpha$-synuclein (BD Biosciences, Franklin Lakes, NJ), anti-synaptotagmin (Santa Cruz Biotechnology, Santa Cruz, CA), anti- $\beta$-tubulin (Sigma), anti-synphilin-1 (Biodesign, Kennebunk, $\mathrm{ME}$ ), and anti-cyclin E (Santa Cruz Biotechnology) antibodies. Detection was performed with enhanced chemiluminescence (Amersham Biosciences).

Animals and stereotaxic injection of $p 38$. All procedures were performed in compliance with the guidelines set forth by the Laboratory Animal Manual of the National Institute of Health Guide to the Care and Use of Animals and were approved by the Johns Hopkins Medical Institute Animal Care Committee. Female BC57 mice were bred and maintained at the animal facility of the Johns Hopkins School of Medicine. They were housed in groups of three per cage in a temperature- and humidity-controlled room with a $12 \mathrm{~h}$ light/dark cycle. Food and water were available ad libitum.

Animals weighing $30 \mathrm{~g}$ were anesthetized with phentobarbital $(60 \mathrm{mg} /$ $\mathrm{kg}$, i.p.). An injection cannula (26.5 gauge) was placed stereotaxically into the SN (anteroposterior, $-3.1 \mathrm{~mm}$ from bregma; mediolateral, $1.3 \mathrm{~mm}$; dorsoventral, $4.3 \mathrm{~mm}$ ) according to the atlas of Paxinos et al. (1985). Injections of adenoviral vectors of p38 were made in $2.5 \mu \mathrm{l}$ of virus solution. The viral suspensions were freshly prepared just before use and were kept on ice before and during the injection. The infusion was done at a rate of $0.2 \mu \mathrm{l} / \mathrm{min}$. The cannula was left in place for $5 \mathrm{~min}$ before slowly withdrawing it to avoid reflux along the injection track. The wound was closed with suture, and the animals were allowed to recover before they were returned to their cage. The entire procedure was well tolerated by the animals.

Immunohistochemistry. Animals were deeply anesthetized $(80 \mathrm{mg} / \mathrm{kg}$ phentobarbital, i.p.) and transcardially perfused with PBS, followed by ice-cold $4 \%$ paraformaldehyde in $0.1 \mathrm{~m}$ phosphate buffer, $\mathrm{pH}$ 7.4. Brains were promptly removed and postfixed in $4 \%$ paraformaldehyde in $0.1 \mathrm{M}$ phosphate buffer, $\mathrm{pH} 7.4$, for $2 \mathrm{~h}$ at room temperature. Each brain was cryoprotected in $30 \%$ sucrose until equilibrated and then stored at $-80^{\circ} \mathrm{C}$ until processed.

Brain tissue was cut into $40 \mu \mathrm{m}$ sections on a HM440E microtome (Microm, Walldorf, Germany), and the sections were collected in the phosphate buffer and incubated in $0.1 \mathrm{~m} \mathrm{PBS,} \mathrm{pH} \mathrm{7.4,} \mathrm{containing} 1 \%$ BSA and $0.2 \%$ Triton X-100. After washing in the rinsing buffer containing the PBS and $0.5 \%$ BSA, the sections were incubated with antisera against tyrosine hydroxylase (TH) (1:2000, polyclonal; Novus Biologicals, Littleton, $\mathrm{CO}$ ) overnight at $4^{\circ} \mathrm{C}$ with shaking. After washes in the rinsing buffer, the sections were incubated for $1 \mathrm{~h}$ in the appropriate biotinylated secondary antisera, washed with the rinsing buffer, and then further incubated for $1 \mathrm{~h}$ in the avidin-biotin complex. Antigens were visualized by reaction with $0.05 \% 3,3^{\prime}$-diaminobenzidine in the presence of $0.003 \%$ hydrogen peroxide. After two washes in the phosphate buffer, the sections were mounted on gelatin-coated slides, dehydrated through graded ethyl alcohols, cleared in xylene, and coverslipped with Permount. To verify whether a reduction in TH cell count necessarily implies cell death, some TH sections were counterstained for Nissl ( $0.2 \%$ cresyl violet for 2 min, followed by dehydration with serial concentration of EtOH), and, for each TH section, an adjacent section was stained with cresyl violet.

For immunostaining, human brain tissue fixed with Formalin and then paraffin embedded sections $(10 \mu \mathrm{m})$ were deparaffinized, treated with $\mathrm{H}_{2} \mathrm{O}_{2}$, blocked with $3 \%$ normal goat serum in TBS, and incubated with anti-p38 polyclonal antibody (1:50) overnight. Subsequently, the tissue was incubated with biotinylated secondary antibodies (anti-rabbit IgG for $1 \mathrm{~h}$ ), and immunoreactions were visualized with the $A B C$ complex (Vector Laboratories, Burlingame, CA) and DAB (Vector Laboratories).

For double immunofluorescence labeling with $\alpha$-synuclein and p38, postmortem brain tissues from PD cases and controls were fixed in $4 \%$ paraformaldehyde overnight, cryoprotected, and frozen. Free-floating $40-\mu \mathrm{m}$-thick sections were blocked with $4 \%$ normal goat serum in TBS and incubated with anti- $\alpha$-synuclein monoclonal antibody (1:5000) (Transduction Laboratories, Lexington, $\mathrm{KY}$ ) and anti-p38 polyclonal antibody (1:500) overnight at $4^{\circ} \mathrm{C}$. Then, the tissue was incubated with cyanine 3-conjugated goat anti-mouse IgG (red color) (Jackson ImmunoResearch, West Grove, PA) and Alexa Fluor goat anti-rabbit IgG (green color) for $4 \mathrm{~h}$. Tissue sections were examined with a Zeiss (Oberkochen, Germany) laser confocal microscope.

Cell counting of SNPc. TH-immunopositive cells in the SNpc were counted as described previously (Yuan et al., 2005). In brief, every fourth section throughout the entire SNpc were scanned under light microscopy, and TH-immunoreactive cells were counted. A cell, when intact, round with clear nucleus, was considered. In the Nissl-stained sections, counting of the cells showing light blue cytoplasm and dark blue nucleus in the SNpc was performed on the adjacent one of the TH-stained section. The number of neurons was expressed as the average of the counts obtained from representative sections.

Statistical analysis. Densitometric analysis of protein bands was analyzed on an AlphaImager 2000 densitometer (Alpha Inotech, Wohlen, Switzerland). Data are expressed as mean \pm SEM. The results were statistically evaluated for significance by applying the unpaired two-tailed test. Differences were considered significant when $p<0.05$.

\section{Results}

The steady-state level of aminoacyl-tRNA synthetase cofactor p38/JTV1 is upregulated in ventral midbrain/hindbrain of

\section{Parkin null mice}

A number of putative substrates have been identified for parkin, but it is not clear which one, if any, are authentic parkin substrates (von Coelln et al., 2004a). Accordingly, we reasoned that authentic parkin substrates should accumulate in both parkin KO mice and AR-JP brains. To identify authentic substrates, we examined via Western blot analysis the level of known putative substrates of parkin in the ventral midbrain/hindbrain of 18month-old parkin null mice compared with ventral midbrain/ hindbrain of age-match controls (Fig. 1). We normalized the 


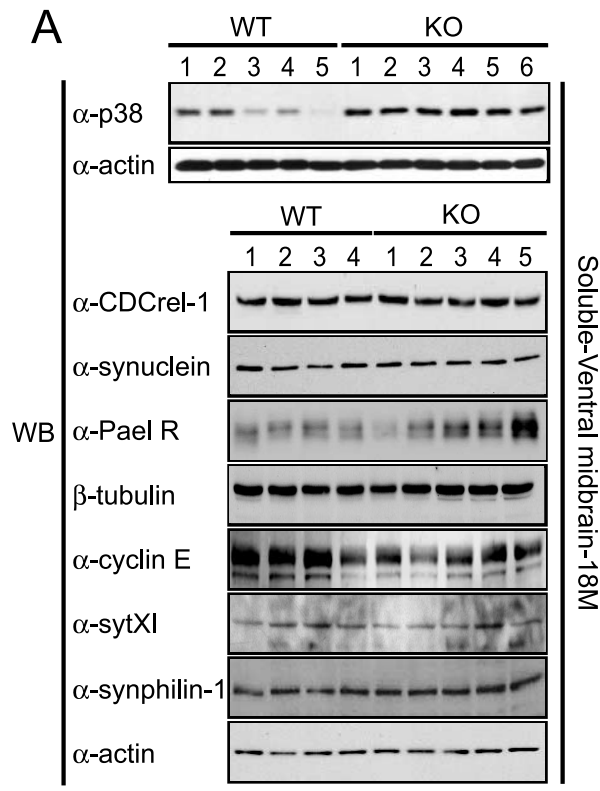

B
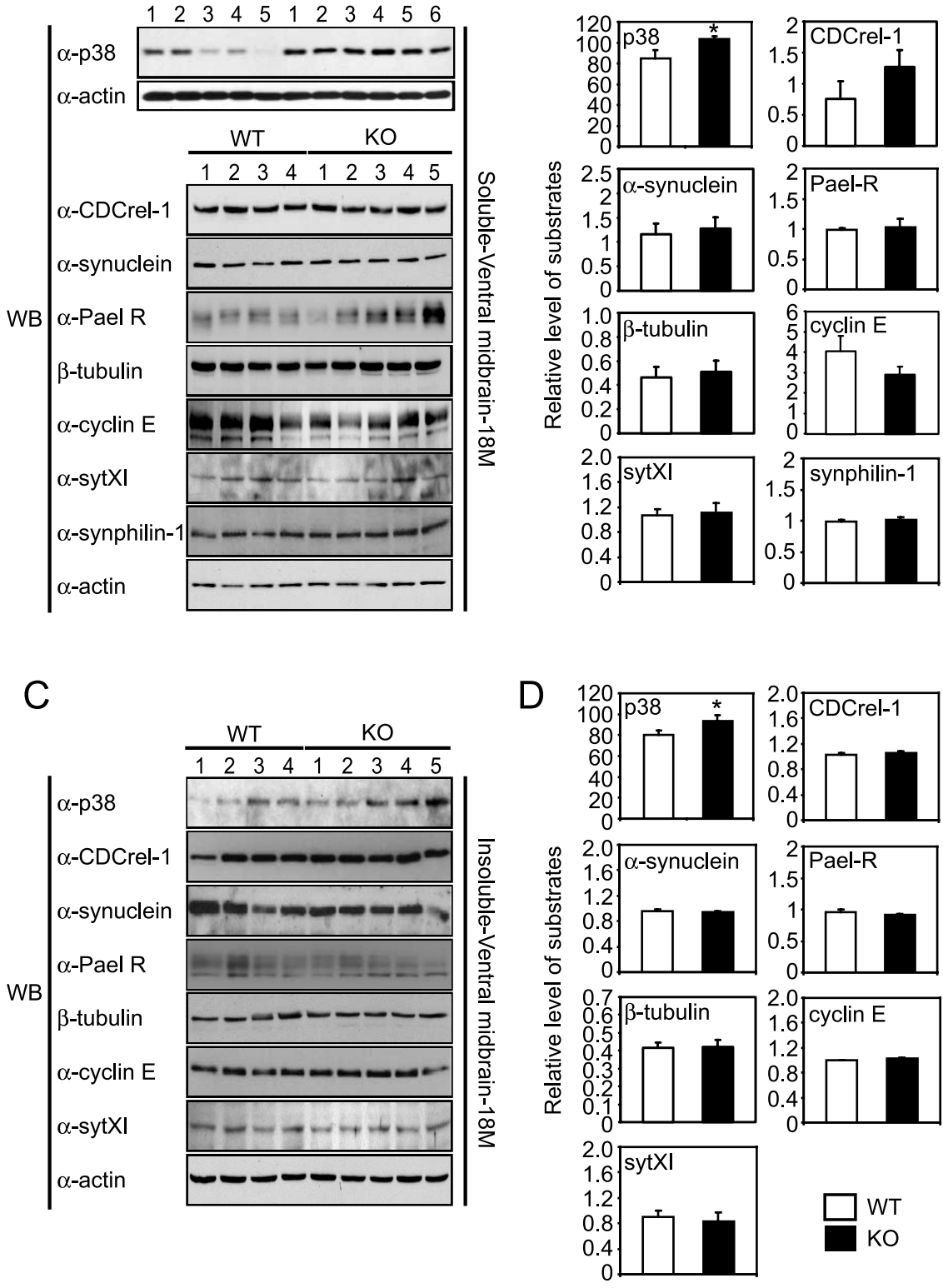

Figure 1. Increased steady-state levels of p38 but not other substrates in parkin null mice. Ventral midbrain/hindbrains of 18-month-old wild-type ( $n=5 / n=4$ animals) and parkin null ( $n=6 / n=5$ animals) mice were homogenized. Soluble $(\boldsymbol{A})$ and insoluble ( $C$ fractions were analyzed by Western blotting with antibodies to p38, CDCrel-1, $\alpha$-synuclein, Pael-R, $\beta$-tubulin, cyclin $\mathrm{E}$, and synaptotagmin XI. Densitometric analyses of band intensities normalized to actin (loading control) are presented as mean $\pm \operatorname{SEM}(\boldsymbol{B}, \boldsymbol{D}) .{ }^{*} p<0.05$, Student's $t$ test.

levels to $\alpha$-actin. We observed significant increased levels of p38 in the both soluble (Fig. $1 A, B$ ) and insoluble (Fig. $1 C, D$ ) extracts compared with wild-type controls. The relative level of p38 is upregulated $18 \%$ in the soluble fraction and $10 \%$ in insoluble fraction, respectively. Western blot analysis and quantification of levels of CDCrel-1, $\alpha$-synuclein, Pael-R, cyclin E, SytXI, and $\beta$-tubulin fail to exhibit any significant change in both soluble (Fig. $1 A, B$ ) and insoluble (Fig. $1 C, D$ ) extracts relative to agematched control brain extracts. These results suggest that, of the putative parkin substrates identified to date, p38 is the only potential authentic substrate.

The specificity of p38 rabbit polyclonal antibody was assessed by preparing extracts from wild-type, heterozygote, and p38 null brain extracts. The p38 antibody only recognizes a single band on
Western blot analysis in wild-type brain, in heterozygote mice, there is reduced immunoreactivity, and in p38 null brain extracts, there is no immunoreactivity, thus confirming the specificity of our polyclonal p38 antibody (Fig. 2 A). To examine whether in vitro knock-out of parkin leads to the accumulation of p38, we isolated adult neuronal stem cells from parkin null mice. We observe a trend toward increased levels of p38 in parkin null neuronal stem cells (Fig. $2 \mathrm{~B}$ ). To determine whether the accumulation of p38 is age dependent, we examined the relative level of p38 in 2-month-old ventral midbrain/hindbrain extracts compared with age-matched wild-type control ventral midbrain/hindbrain extracts (Fig. 2C). We observed a statistically significant accumulation (relative level of p38 is $15 \%$ ) of p38 in ventral midbrain/hindbrain at 2 months of age (Fig. $2 C)$. Next, to determine whether p38 accumulates in other brain regions, we examined the level of p38 in cortex of 2 and 18 months of age (Fig. 2D,E) and cerebellum, brainstem, and striatum at 18 months of age (Fig. $2 F$ ). We failed to observe a significant increase in p38 in cortex, cerebellum, brain stem, and striatum of parkin null mice versus age-matched wild-type controls (Fig. $2 D-F$ and data not shown). Together, these results suggest that p38 accumulates primarily in the midbrain/ hindbrain of parkin knock-out mice.

\section{p38 accumulates in AR-JP, PD, and DLB disease}

To ascertain whether the upregulation of p38 in parkin knock-out mice has potential pathophysiologic relevance, Western blot analysis was performed from AR-JP cortex, and the level of p38 was compared in age-matched controls. Increased levels of p38 in AR-JP brains is observed compared with controls (Fig. 3A). To determine whether the other putative parkin substrates accumulate in AR-JP brains, we assessed the level of CDCrel-1, synphilin-1, $\alpha$-synuclein, Pael-R, cyclin E, SytXI, and $\beta$-tubulin (Fig. 3B). No significant increase in the levels of CDCrel-1, $\alpha$-synuclein, synphilin-1, Pael-R, cyclin E, and $\beta$-tubulin are observed in AR-JP brains compared with control (Fig. 3B). Recent data suggest that parkin is $S$-nitrosylated in vitro and in vivo and that $S$-nitrosylation inhibits the ubiquitin E3 ligase activity of parkin (Chung et al., 2004). Inhibition of the ubiquitin E3 ligase activity of parkin should lead to the accumulation of parkin substrates in PD and DLB disease (DLBD) brains with increased $S$-nitrosylated parkin. Accordingly, we examined whether the level of p38 is altered in sporadic PD and DLBD with increased $S$-nitrosylated parkin. Interestingly, p38 accumulates in brains from patients with PD and DLBD with $S$-nitrosylated parkin compared with controls (Fig. $3 C$ ). We next examined the distribution of $\mathrm{p} 38$ in the PD and control SN pars compacta. 
A
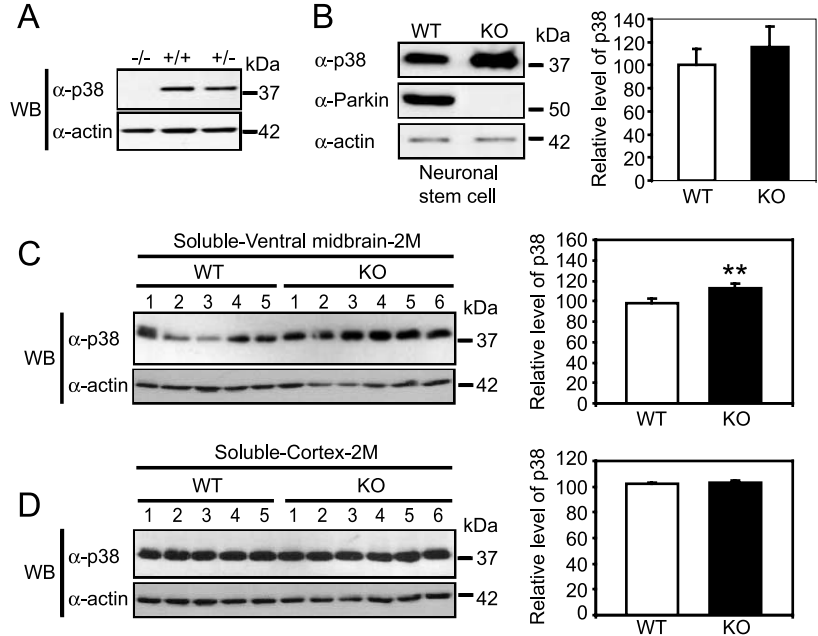

$\mathrm{E}$
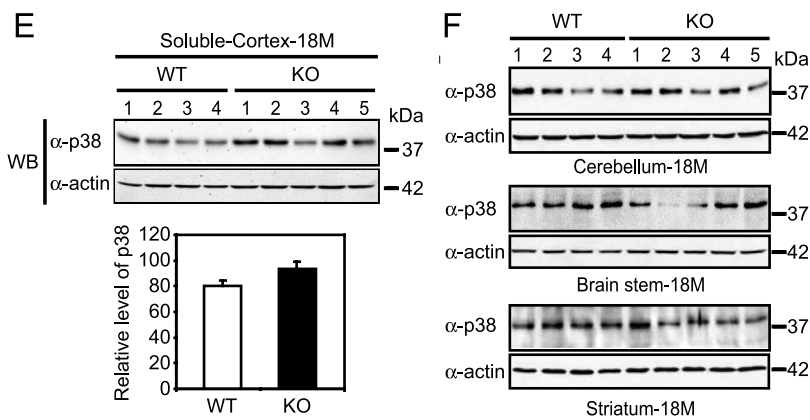

Figure 2. Significant accumulation of $\mathrm{p} 38$ in ventral midbrain/hindbrain of 2-month-old parkin null mice. $A$, Specificity of polyclonal antibodies to $\mathrm{p} 38$ was confirmed on a Western blot (WB) against brain homogenates from p38 null $(-/-)$, wild-type $(+/+)$, and heterozygous $(+/-)$ mice (top). The blot was stripped and reprobed with an anti-actin antibody to confirm equivalent loading in all lanes (bottom). $\boldsymbol{B}$, Cell extracts $(40 \mu \mathrm{g}$ ) of adult neuronal stem cells isolated from parkin null and wild-type mice were subjected to SDS-PAGE and probed on a Western blot with anti-p38 (top), anti-parkin (middle), and anti-actin (bottom). C, Soluble fraction of brain lysates from ventral midbrain/hindbrain of 2-month-old wild-type and parkin null mice were subjected to SDS-PAGE and probed on a Western blot with anti-p38 (top) and anti-actin (bottom) antibodies. Densitometric analyses of band intensities normalized to actin levels are presented as mean \pm SEM. ${ }^{* *} p<0.005$, Student's $t$ test. $\boldsymbol{D}$, Lysates $(40 \mu \mathrm{g}$ ) prepared from cortex of 2-month-old wild-type and parkin null mice were analyzed for immunoreactivity to anti-p38 and anti-actin antibodies. $\boldsymbol{E}, \boldsymbol{F}$, Lysates $(40 \mu \mathrm{g})$ prepared from cortex $(\boldsymbol{E})$, cerebellum, brainstem, and striatum $(\boldsymbol{F})$ of 18-month-old wild-type and parkin null mice were analyzed by Western blotting with antibodies to $\mathrm{p} 38$ and actin. Densitometric analysis is presented for cortex as mean \pm SEM (E).

Granular immunoreactivity for $\mathrm{p} 38$ is present in the perikaryon of pigmented neurons in control and PD SN pars compacta (Fig. $3 D)$. p38 appears contained in vesicular structures admixed with neuromelanin. In addition, we also examined whether p38 was expressed in other cell types in brain. P38 is widely expressed throughout the brain in both neurons and glia (data not shown). Next, to determine whether p38 is localized to Lewy bodies, double-labeled midbrain sections from PD subjects with $\alpha$-synuclein and p38 were examined. Double immunofluorescent labeling and confocal analysis of neuromelanin containing neurons reveals diffuse cytoplasmic vesicular immunoreactivity for p38 (green) in close proximity to $\alpha$-synuclein-labeled Lewy bodies (red). At the center of Lewy bodies, there is colocalization of both proteins (yellow) (Fig. 3D). These results together indicated that p38 accumulates in AR-JP and in PD/DLBD with defective parkin function attributable to $S$-nitrosylation. Moreover, p38 is localized within dopaminergic neurons and accumulates within Lewy bodies.
Parkin interacts with aminoacyl-tRNA synthetase p38

The accumulation of p38 in parkin knock-out midbrain/hindbrain, AR-JP brains, and PD/DLBD brains with $S$-nitrosylative stress suggests that p38 interacts with parkin. To further characterize the interaction of $\mathrm{p} 38$ with parkin, a GST pull-down assay was performed (Fig. 4A). The fusion protein GST-p38 was expressed, purified, and incubated with in vitro-translated ${ }^{35} \mathrm{~S}$-Metlabeled parkin and parkin 77-465. After extensive washing, the proteins bound to glutathione-Sepharose beads were separated by SDS-PAGE and detected by autoradiography. GST-p38 (lane 2 ), but not GST alone (lane 1), is able to efficiently retain parkin and parkin 77-465 (Fig. 4A).

To investigate the physical interaction in vivo, immunoprecipitation was performed using the human neuroblastoma cell line SH-SY5Y (Fig. 4B) and human brain homogenates (Fig. 4C). Cotransfection experiments with myc-tagged p38 and HAtagged parkin were performed, followed by coimmunoprecipitation using the anti-myc antibody. p38 coimmunoprecipitates with parkin after cotransfection in SH-SY5Y cells (Fig. 4B). To determine whether $\mathrm{p} 38$ interacts with parkin in human brain, coimmunoprecipitation using an antibody against parkin from human cortex was performed, followed by Western blot analysis with a monoclonal antibody against p38. p38 coimmunoprecipitates with parkin from human cortex, whereas the immunoprecipitation with anti-myc or anti-HA antibodies fails to immunoprecipitate p38 (Fig. 4C). We also observed that p38 strongly coimmunoprecipitates with parkin from human midbrain and striatum (data not shown). We next monitored whether the interaction of parkin and p38 is disrupted or altered by familial$\mathrm{PD}$-associated mutations in parkin. Myc-tagged wild-type and mutant parkin, R42P and Q311stop, were transiently transfected into SH-SY5Y cells along with HA-tagged p38 to examine the relative binding abilities of $\mathrm{p} 38$ to wild-type versus mutant parkin. The R42P mutation in parkin reduces its ability to interact with $\mathrm{p} 38$, whereas the Q311stop mutant binds more avidly to p38 then wild-type parkin (Fig. 4D). Parkin exists in a macromolecular protein complex with CHIP and Hsp70, in which this complex participates in the ubiquitination and degradation of parkin substrates (Imai et al., 2002). To determine whether p38 interacts with components of this parkin complex, we performed coimmunoprecipitation to monitor the ability of FLAG-p38 to interact with HA-tagged CHIP or V5-tagged Hsp70 (Fig. 4E, F). We find that p38 interacts with CHIP (Fig. 4E) and Hsp70 (Fig. 4F). To explore whether the interaction of p38 is influenced by proteasomal degradation, we examined the interaction of parkin and p38 after the administration of the proteasome inhibitor MG132, before the immunoprecipitation. MG132 significantly increases the amount of $\mathrm{p} 38$ coimmunoprecipitated with parkin (Fig. 4G). Together, these results indicate that parkin interacts with $\mathrm{p} 38$ both in vitro and in vivo and that the interaction of p38 with parkin is part of a macromolecular complex composed of CHIP and Hsp70. Moreover, familial-associated parkin mutants alter the interaction of parkin with $\mathrm{p} 38$.

\section{p38 interacts with parkin through its RING1 domain, and} parkin associates with $\mathrm{p} 38$ through its $\mathrm{N}$-terminal domain To ascertain which domain of parkin binds to $\mathrm{p} 38$, various deletion constructs of myc-tagged parkin were constructed (Fig. 5A). Each truncated construct was coexpressed with HA-tagged p38 in SH-SY5Y cells. After $48 \mathrm{~h}$ of transfection, protein extracts were immunoprecipitated with anti myc-conjugated agarose, followed by Western blot analysis with anti-HA antibody (Fig. 5A). WT parkin and mutants containing the RING1 (R1) domain interact 
A

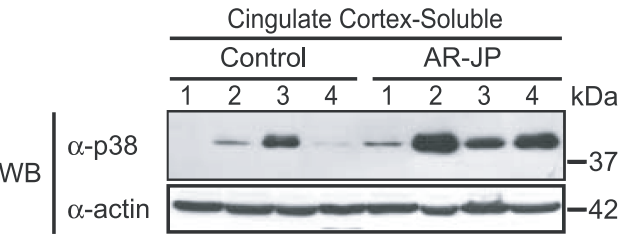

B
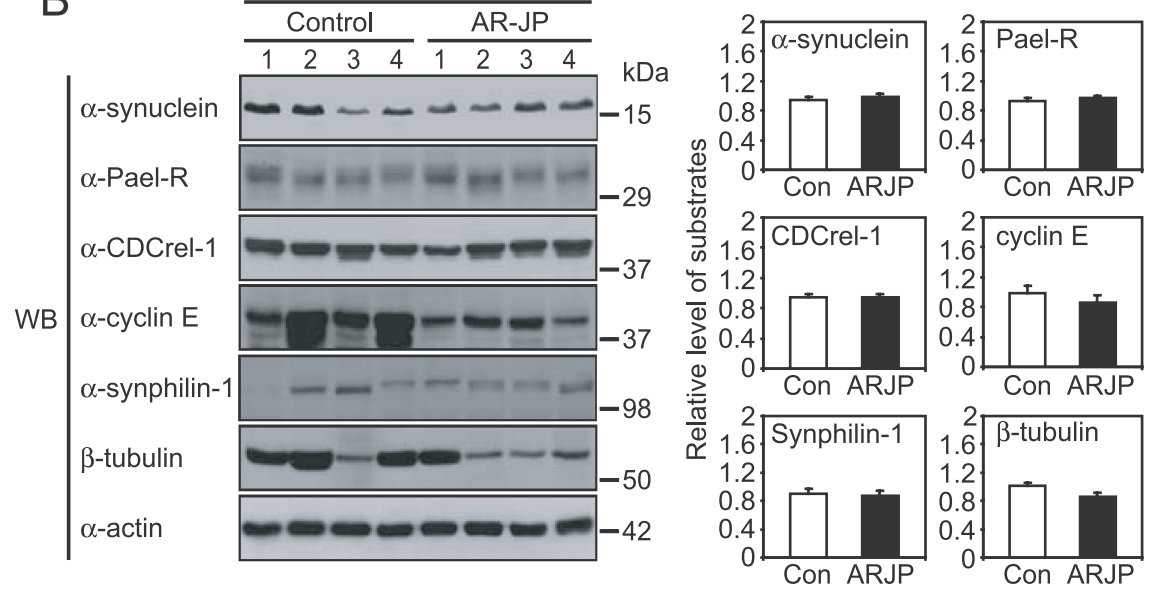

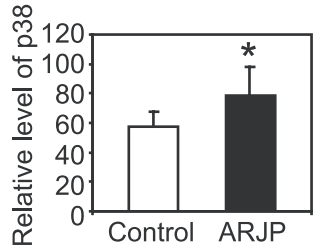

Cingulate Cortex-Soluble

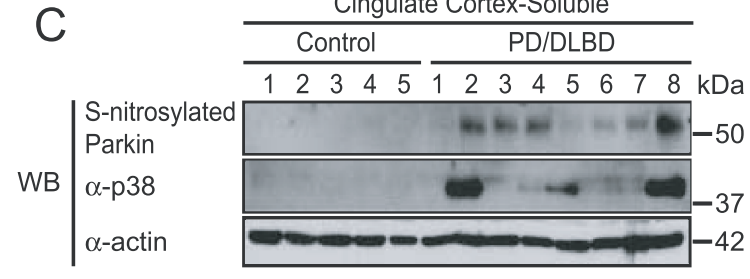

Control

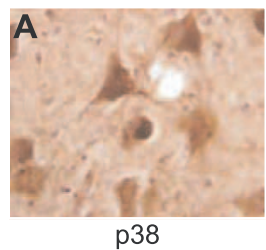

lowed by coimmunoprecipitation using anti-myc (Fig. 5B). Truncated p38 containing the whole or part of the 82-162 domain (WT, F1, F3, and F4) interact with parkin. However, truncated p38 lacking amino acid residues $82-162$ fails to interact with the fulllength parkin. This mapping study indicates that parkin mainly interacts with the 82-162 amino acid domain of p38 (Fig. 5B).

Parkin ubiquitinates p38, and familiallinked parkin mutations interfere with p38 proteasomal degradation

To determine whether parkin ubiquitinates p38, in vivo ubiquitination experiments were examined. SH-SY5Y cells were cotransfected with FLAG-tagged p38, myc-tagged parkin, and HA-tagged ubiquitin, and FLAG-p38 was immunoprecipitated with an anti-FLAG antibody from the total cell extract. p38 is ubiquitinated by parkin, as shown by the significant anti-HA immunoreactivity (Fig. 6, top panel, lane 4) and anti-FLAG (Fig. 6, middle panel, lane 4) in the form of smear, which is characteristic of polyubiquitinated proteins, suggesting that parkin ubiquitinates p38. To examine whether familiallinked parkin mutations affect the parkinmediated ubiquitination of p38 (Fig. 6, lanes $5,6)$, we cotransfected SH-SY5Y cells with FLAG-tagged p38, myc-tagged Q311Stop, R42P, and HA-tagged ubiquitin, and immunoprecipitated FLAG-p38 with an antiFLAG antibody. We find that Q311Stop mutant impairs the ability of parkin to ubiquitinate p38, whereas the R42P mutant enhances p38 ubiquitination, suggesting that the two mutants affected parkin function by distinct mechanisms.

Multi-ubiquitinated substrates are degraded by the $20 \mathrm{~S}$ proteolytic subunits of $26 \mathrm{~S}$ proteasome. To evaluate whether parkinubiquitinated p38 might be a target for degradation by $26 \mathrm{~S}$ proteasome, we stably transfected SH-SY5Ycells with HA-tagged p38 and determined whether parkin promotes p38 degradation of HA-tagged p38 by analyzing the steady-state level of $\mathrm{p} 38$. There is a dose-dependent decrease in p38 in the presence of parkin (Fig. 7A), and the proteasome inhibitors MG132 (5 $\mu \mathrm{M})$ and $\beta$-lactacystin $(10 \mu \mathrm{M})$ prevent the decrease in the steadystate level of p38 leading to an accumulation of p38 (Fig. $7 B$ ). The levels of p38 in SHSY5Ycells transfected with WT, Q311Stop, with p38, whereas mutants lacking R1 domain fail to interact with p38 (Fig. 5A). These data suggest that amino acid residues $220-$ 318, which contain the RING1 domain, are important for the interaction of parkin with p38. Next, we constructed a series of myc-tagged truncated $\mathrm{p} 38$ constructs to determine the domain of p38 that interacts with parkin (Fig. $5 B$ ). The series of truncation of myc-tagged p38 were coexpressed with HA-tagged parkin and foland R42P parkin were compared, and the Q311Stop and R42P mutant parkins failed to lower the steady-state level of p38, whereas WT parkin lowered the steady-state level of stably transfected p38 (Fig. $7 C$ ). These results together indicate that parkin promotes the degradation of p38 through the ubiquitin-proteasome pathway and that familial-associated mutations in parkin impair the proteasomal degradation of $\mathrm{p} 38$. 
A
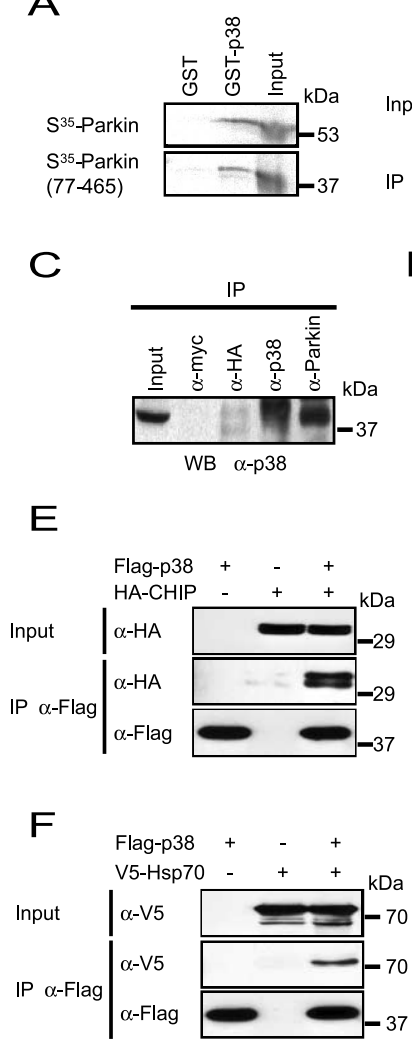

B

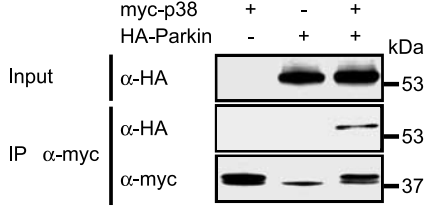

D
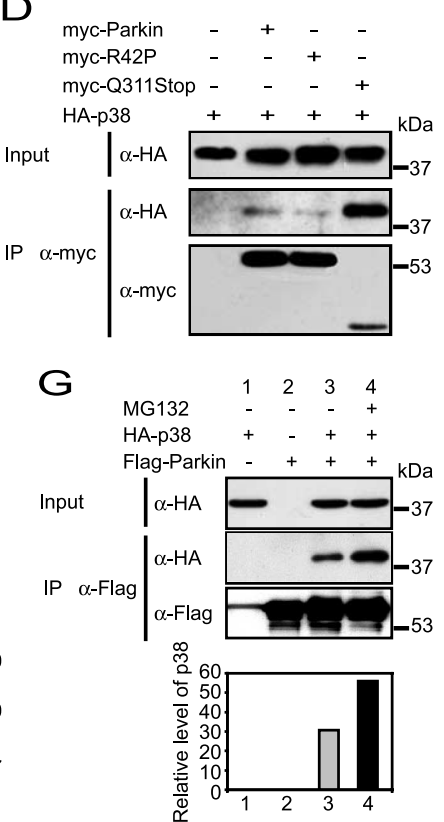

Figure 4. Parkin interacts with aminoacyl-tRNA synthetase cofactor p38/JTV-1. A, GST-pull down of parkin by p38. GST-p38 was incubated with in vitro-translated ${ }^{35}$ S-Met-labeled wildtype and UBL-deleted (77-465) parkin. Proteins bound to glutathione-Sepharose beads were washed extensively, subjected to SDS-PAGE, and detected by autoradiography. Both wild-type and 77-465 parkin were efficiently retained by GST-p38 (lane 2) but not GST alone (lane 1). $\boldsymbol{B}$ Parkin and p38 interact in SH-SY5Y cells. Lysates prepared from SH-SY5Y cells transfected with myc-tagged p38 and HA-tagged parkin were subjected to immunoprecipitation (IP) with antimyc, followed by anti-HA immunoblotting (middle). The blot was stripped and reprobed with anti-myc antibody (bottom) to show an equivalent amount of immunoprecipitated p38. C, Coimmunoprecipitation of $\mathrm{p} 38$ and parkin from human brain extract. Human frontal cortex homogenate was subjected to immunoprecipitation with anti-myc, anti-HA, anti-p38, or antiparkin, followed by immunoblotting with a monoclonal antibody to p38. D, Familial-associated mutations in parkin alter the interaction with p38. Lysates prepared from SH-SY5Y cells transfected with HA-tagged $\mathrm{p} 38$ and myc-tagged wild-type, R42P, or Q311Stop parkin constructs were subjected to immunoprecipitation with anti-myc, followed by anti-HA immunoblotting (middle). The blot was stripped and reprobed with anti-myc to show levels of immunoprecipitated parkin (bottom). $E$, p38 interacts with CHIP. Lysates from SH-SY5Y cells transfected with FLAG-tagged p38, HA-tagged CHIP, or both were subjected to immunoprecipitation with antiFLAG, followed by anti-HA immunoblotting (middle). The blot was stripped and reprobed with anti-FLAG to show equivalent amounts of immunoprecipitated p38 (bottom). $\boldsymbol{F}$, p38 interacts with Hsp70. Lysates from SH-SY5Y cells transfected with FLAG-tagged p38, V5-tagged Hsp70, or both were immunoprecipitated with anti-FLAG, followed by immunoblotting with anti-V5 (middle) and anti-FLAG (bottom). G, Treatment with proteasome inhibitor promotes the interaction between parkin and $\mathrm{p} 38$. SH-SY5Y cells were transfected with HA-tagged $\mathrm{p} 38$ and FLAGtagged parkin, followed by treatment with proteasome inhibitor MG132 $(5 \mu \mathrm{M})$ for $18 \mathrm{~h}$. Lysates were subjected to immunoprecipitation with anti-FLAG antibody, followed by Western blotting with anti-HA (middle) and anti-FLAG (bottom).

\section{p38 overexpression leads to neuronal toxicity in vitro and} in vivo

To address the functional significance of the interaction of p38 with parkin, we examined the role of p38 in cell death. Overexpression of myc-tagged p38 in native SK-N-MC cells causes an almost threefold increase in cell death compared with mocktransfected cells, and coexpression of FLAG-parkin partially pro-

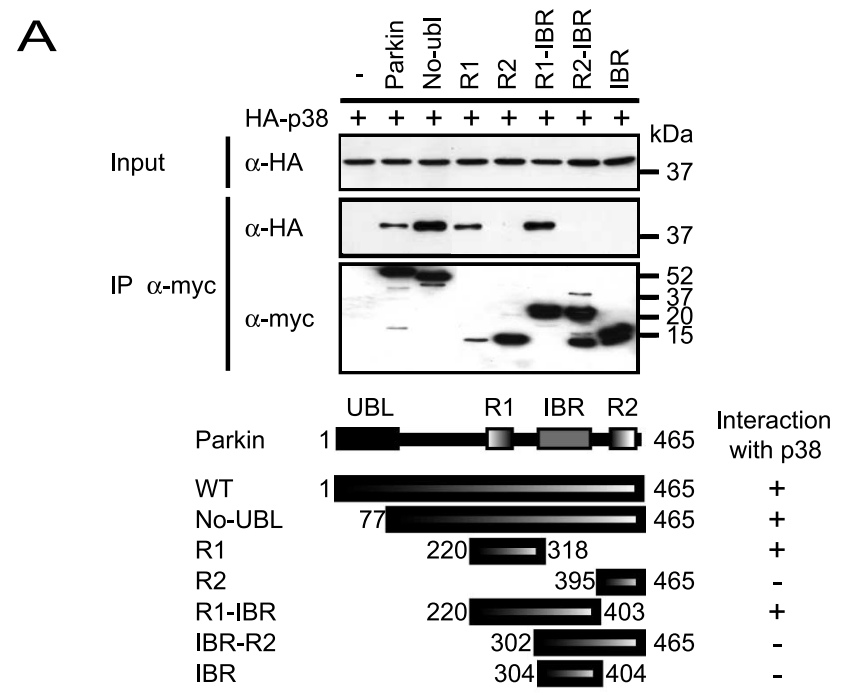

B

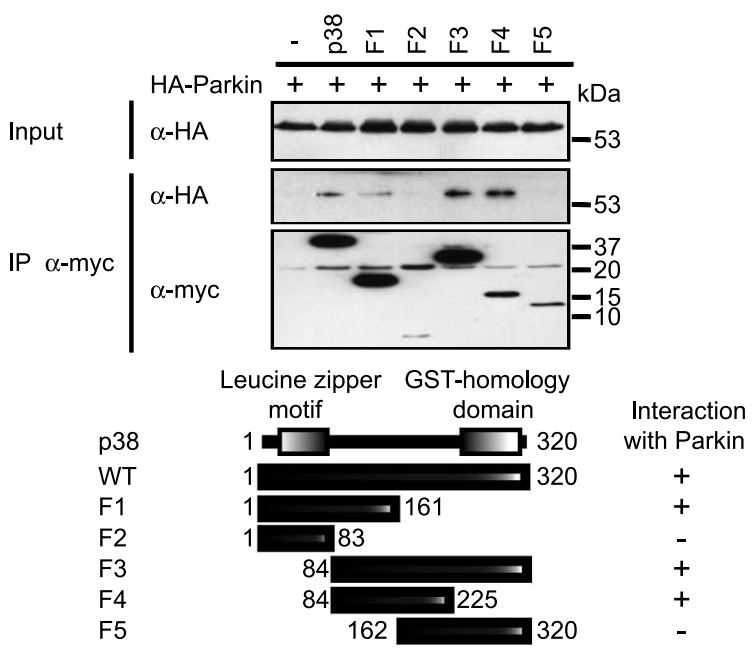

Figure 5. p38 interacts with the R1 ring finger domain of parkin, and parkin associates with the N-terminal domain of p38. A, Lysates from SH-SY5Y cells transfected with HA-p38 and various myc-tagged parkin domain constructs were subjected to immunoprecipitation (IP) with anti-myc, followed by anti-HA immunoblotting (middle). The blot was stripped and reprobed with anti-myc to illustrate the levels of parkin constructs that were expressed (bottom). Putative functional domains of parkin used in the mapping experiments are shown at the bottom of the figure. $\boldsymbol{B}$, Lysates prepared from SH-SY5Y cells transfected with HA-tagged parkin and various myc-tagged fragments of $\mathrm{p} 38$ were subjected to immunoprecipitation with anti-myc antibodies, followed by anti-HA immunoblotting (middle). The blot was stripped and reprobed with anti-myc to show the relative levels of immunoprecipitated $\mathrm{p} 38$ fragments (bottom). A schematic representation of the different $p 38$ fragments used in the mapping experiments is shown.

tects from $\mathrm{p} 38$-induced toxicity but R42P mutant parkin fails to the rescue (Fig. $8 \mathrm{~A}$ ). Moreover, overexpression of $\mathrm{p} 38$ enhances the sensitivity of human neuroblastoma SK-N-SH to TNF $\alpha$ more than twofold (Fig. $8 B$ ). The enhancement of TNF $\alpha$ toxicity by p38 is prevented by overexpression of parkin, whereas the familial-associated parkin mutation R42P fails to protect (Fig. $8 \mathrm{~B}$ ). These results indicate that $\mathrm{p} 38$ overexpression induces cell death in neuroblastoma cells and enhances their sensitivity to TNF $\alpha$. We next sought to determine whether overexpression of p38 in dopaminergic neurons leads to cell death in vivo (Fig. 8C). High-titer rAV-expressing p38 and enhanced green fluorescent protein (EGFP) as a control were injected stereotactically in the dorsal SNc of the right hemisphere of mice. Expression of p38 and EGFP could be detected in the majority of TH-positive neu- 


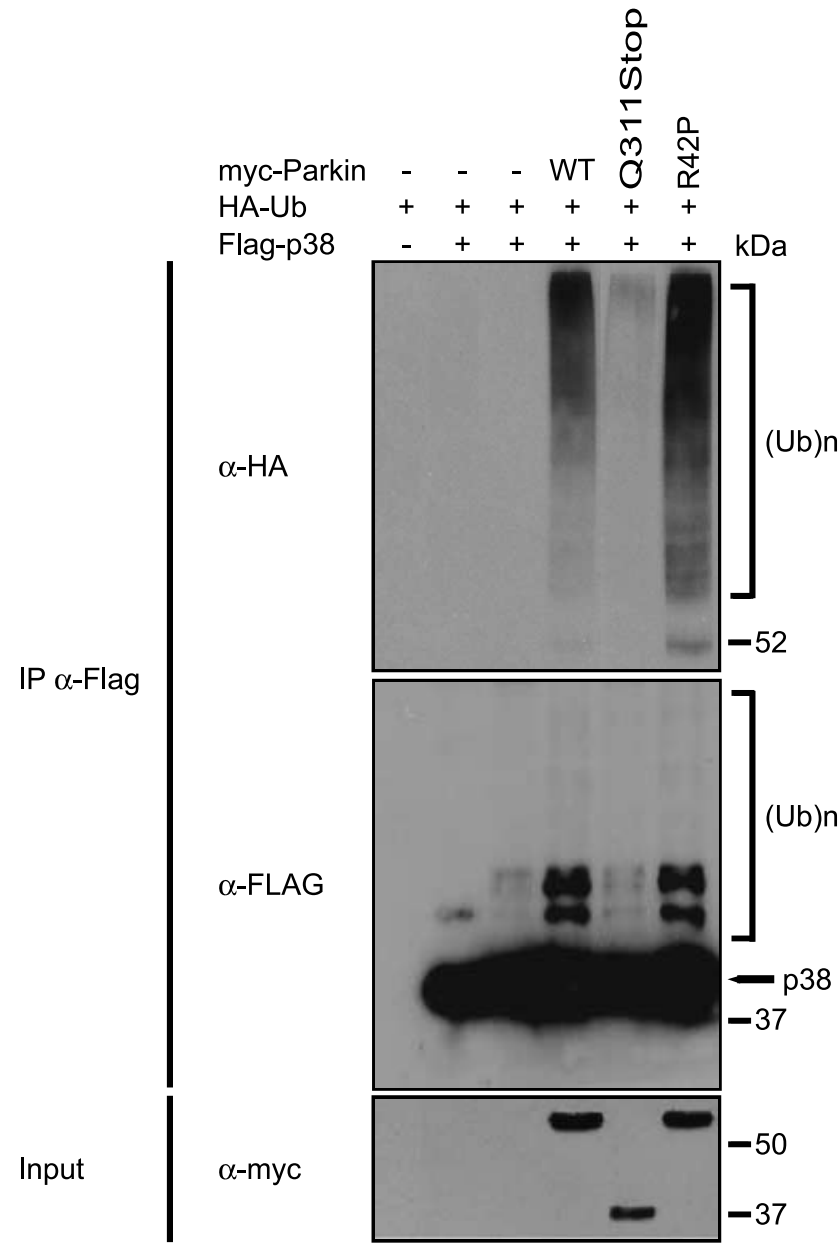

Figure 6. Parkin ubiquitinates $\mathrm{p} 38$, and familial-associated mutations in parkin alter the ubiquitination of $\mathrm{p} 38$. Lysates prepared from SH-SY5Y cells transfected with myc-tagged wildtype, Q311Stop or R42P parkin, HA-tagged ubiquitin, and FLAG-tagged p38 were subjected to immunoprecipitation (IP) with anti-FLAG, followed by immunoblotting with anti-HA (top) and anti-FLAG (middle). Lysates were also probed with an anti-myc antibody to show parkin expression (bottom). Arrow indicates immunoprecipitated p38, and brackets indicate ubiquitinated p38.

rons at $10 \mathrm{~d}$ after $\mathrm{rAV}$ injection (data not shown). No reduction in $\mathrm{TH}$-staining is observed in the SNc of animals injected with EGFP (Fig. 8Ca,Cb), despite efficient and sustained EGFP expression in the majority of dopamine neurons (data not shown). However, in mice injected with $\mathrm{rAV}$-expressing $\mathrm{p} 38$, there is a significant loss of the TH-positive neurons at 6 weeks (Fig. $8 C c, C d$ ). Quantification of loss of TH-positive neurons reveals an average loss of $35.258 \pm 6.99 \%(p<0.05)$.

In addition, a significant reduction in cell number is also observed after Nissl staining of p38-injected SNpc compared with the respective contralateral side $(30.92 \pm 3.63 \%$ reduction; $p<$ 0.01 ) (Fig. $8 C e, C f$ ). Together, these results show that p38 overexpression in dopamine neurons leads to cell death.

\section{Discussion}

The major findings of the current study are that the aminoacyltRNA synthetase (ARS) cofactor p38/JTV-1 is an authentic parkin substrate and that overexpression of p38 in dopaminergic neurons leads to cell death. p38 accumulates in the ventral midbrain/hindbrain of parkin knock-out mice, AR-JP brains, and $\mathrm{PD} / \mathrm{DLBD}$ brains with evidence of nitrosative stress. Moreover, we confirm and extend previous observations that parkin inter-
A
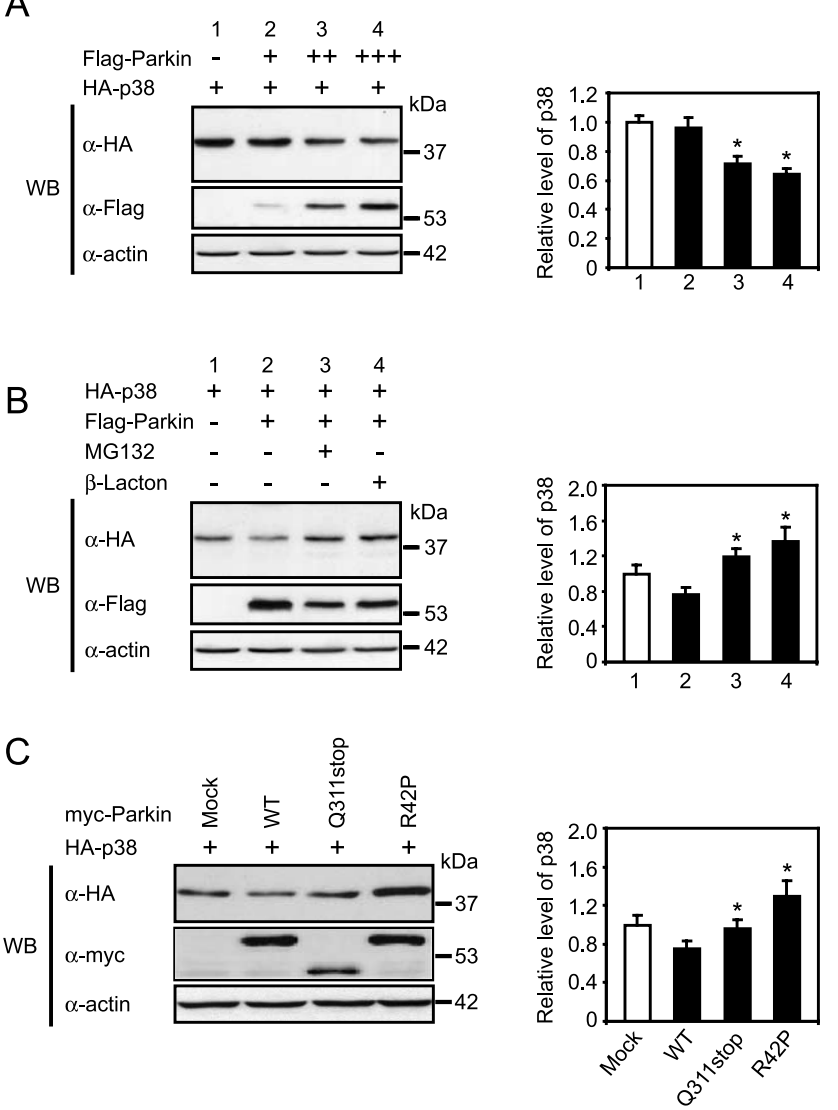

Figure 7. $\quad$ p38 is degraded by the proteasome. A, SH-SY5Y cells stably expressing HA-tagged p38 were transiently transfected with increasing concentrations of FLAG-parkin. Lysates were immunoblotted with anti-HA antibody to show the steady-state levels of p38 (top). The blot was stripped and reprobed with anti-FLAG (middle) to show relative levels of parkin and with anti-actin to confirm equivalent loading (bottom). Densitometric analyses of relative band intensities of $\mathrm{p} 38$ normalized to actin are presented as the mean \pm SEM of three independent experiments. ${ }^{*} p<0.05$, Student's $t$ test. $\boldsymbol{B}$, SH-SY5Y cells stably expressing HA-tagged $p 38$ were transiently transfected with FLAG-parkin and treated for $18 \mathrm{~h}$ with DMSO vehicle (lane 2), $5 \mu \mathrm{m}$ MG132 (lane 3), or $10 \mu \mathrm{m}$ lactacystin (lane 4) before harvesting. Lysates (20 $\mu \mathrm{g}$ ) were analyzed on a Western blot (WB) by immunoblotting with anti-HA (top). The blot was also stripped and reprobed with anti-FLAG (middle) to show relative expression of parkin and with anti-actin (bottom) to confirm equivalent loading in all lanes. Densitometric analyses of relative p38 band intensities normalized to actin are presented as the mean \pm SEM of three independent experiments. ${ }^{*} p<0.05$, Student's $t$ test. C, SH-SY5Y cells stably expressing HA-tagged p38 were transiently transfected with mock vector or myc-tagged wild-type, R42P, and Q311Stop parkin. Cell lysates were analyzed by immunoblotting with anti-HA antibody (top). The blot was stripped and reprobed with anti-myc to show the expression of parkin (middle) and with anti-actin to confirm equivalent loading (bottom). Densitometric analyses of relative p38 band intensities normalized to actin are presented as the mean \pm SEM of three independent experiments. ${ }^{*} p<0.05$, Student's $t$ test.

acts with p38, leading to its ubiquitination and subsequent proteasomal degradation (Corti et al., 2003). The majority of p38 degradation seems to be mediated through the ubiquitin proteasome system and not through chaperone-mediated autophagy (CMA) because p38 does not contain a CMA recognition motif (Cuervo, 2004).

Parkin interacts with p38 through the RING finger 1 domain. The RING-IBR-RING domain binds to specific coenzymes, such as UbcH7, UbcH8, Hsp70, CHIP (Zhang et al., 2000; Imai et al., 2002), and substrates. Other substrates, such as CDCrel-1, synphilin-1, and Pael-R, bind the R2 RING finger domain (Zhang et al., 2000; Chung et al., 2001; Imai et al., 2001). Several studies show that the RING-IBR-RING domain is required for 
A

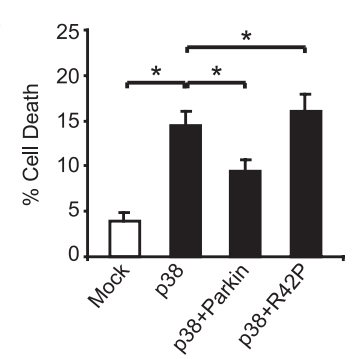

B

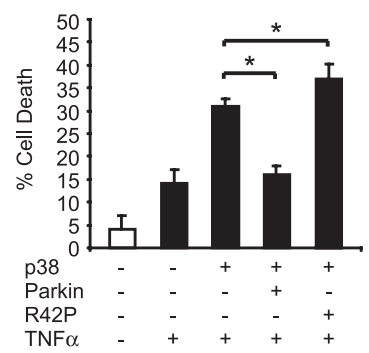

C

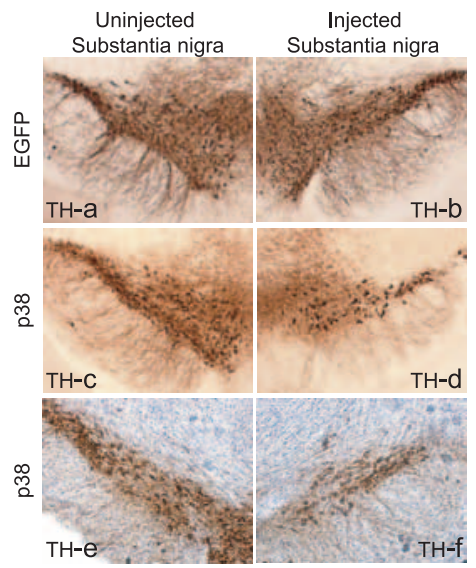

Figure 8. p38 overexpression leads to neurotoxicity in vitro and in vivo. A, Human SK-N-MC neuroblastoma cells were transiently transfected with mock vector, HA-tagged p38 only, or myc-tagged parkin and R42P together with HA-tagged p38. Cell death was assessed by trypan blue staining. Data are shown as the mean \pm SEM for three independent experiments. ${ }^{*} p<$ 0.05 , Student's $t$ test. $\boldsymbol{B}$, Human SK-N-SH neuroblastoma cells were transiently transfected with mock vector, HA-tagged p38 only, or myc-tagged wild-type and R42P parkin together with HA-tagged p38 and treated with TNF $\alpha$ for $4 \mathrm{~h}$. Cell death was determined by trypan blue staining. Data are shown as the mean \pm SEM for three independent experiments. ${ }^{*} p<0.05$, Student's $t$ test. C, Recombinant adenovirus expressing p38 and EGFP (control) were injected stereotactically into the dorsal substantia nigra pars compacta of mice. Six weeks after injection, brain slices were stained with antisera against TH. TH-immunoreactive neurons in the substantia nigra pars compacta were counted in a blind manner. Representative slices for uninjected ( $\boldsymbol{a}$, $\boldsymbol{c}$, and $\boldsymbol{e}$ with Nissl counterstain) and EGFP- ( $\boldsymbol{b}$ and $\boldsymbol{e}$ with Nissl counterstain) or p38- ( $\boldsymbol{d}$ and $\boldsymbol{f}$ with Nissl counterstain) injected mice are shown.

ubiquitin ligase activity, which suggests that binding of p38 to this region is important for the ability of parkin to ubiquitinate the protein. p38 contains two functional domains, such as leucine zipper domain at its $\mathrm{N}$ terminus, which is involved in macromolecular assembly of ARSs (Quevillon et al., 1999; Ahn et al., 2003) and a GST-homology domain at the C terminus. We did not observe an interaction with parkin in these functional domains; instead, mapping studies indicate that parkin mainly interacts with the 82-162 domain of p38. We also discovered that p38 may be capable of forming a protein complex with parkin, CHIP, and Hsp70. CHIP/Hsp70 appear to facilitate the function of parkin (Imai et al., 2002). However, we did not demonstrate the role of the complex of Hsp70, CHIP, and parkin in p38 turnover, so we assume that the Hsp70/CHIP chaperone system may play an important role in p38 biology, such as the regulation of ubiquitination, turnover, and cell death.

The wide variety of parkin mutations discovered in AR-JP patients is hypothesized to result in a loss of the ubiquitin ligase activity of parkin. Because wild-type parkin binds and ubiquitinates p38, targeting it for degradation to the proteasome, we studied the effect of two mutations in parkin, a missense point mutation (R42P) and a nonsense point mutation (Q311Stop), on their relative ability to bind, ubiquitinate, and degrade p38. Coimmunoprecipitation studies showed that both mutants are defective in binding p38; whereas the R42P mutant decreases the ability of parkin to bind p38, the Q311Stop mutant shows enhanced binding. In addition, the ubiquitination profile of p38 in the presence of these parkin mutants is also disrupted. The Q311Stop mutation abolishes the ability of parkin to ubiquitinate p38, whereas the R42P mutation increases the ubiquitin modification on p38 compared with wild-type parkin. Although these familial-associated mutations are observed to have different effects on the function of parkin, both mutants failed to enhance the degradation of $\mathrm{p} 38$. The increased accumulation of $\mathrm{p} 38$ with the Q311Stop mutant may be explained by its diminished ability to ubiquitinate p38. Furthermore, the observed enhanced interaction between p38 and the Q311Stop mutant suggests a role for the $\mathrm{C}$-terminal portion of parkin in substrate binding and release. The R42P point mutation lies in the ubiquitin-like domain of parkin, which is predicted to interact with the proteasome (Sakata et al., 2003). Thus, this mutation may result in a disrupted targeting of ubiquitinated p38 to the proteasome, accounting for the accumulation of substrate with the R42P mutant. Thus, whereas the Q311Stop mutant may result in the accumulation of non-ubiquitinated $\mathrm{p} 38$, the $\mathrm{R} 42 \mathrm{P}$ mutant, which retains its ubiquitin ligase activity, may result in the accumulation of ubiquitinated p38, both of which could be potentially toxic to the cell.

Mutations in parkin are thought to be the most common cause of inherited PD, with the frequency of the mutations estimated at 50\% in families with AR-JP (Lucking et al., 2000). As noted above, parkin mutations are thought to result in loss of the ubiquitin E3 ligase activity of parkin. It has been proposed that the loss-of-function mutations of parkin might impair the removal of parkin substrates, leading to their accumulation followed by ubiquitin-proteasome system dysfunction-induced neurodegeneration (Kahle and Haass, 2004). This hypothesis has been questioned recently because parkin exon 3 knock-outs fail to accumulate substrate (Goldberg et al., 2003). However, in the current study, we find that p38 is upregulated in ventral midbrain/hindbrain extracts of both young- and old-aged parkin null mice, whereas none of the other reported parkin substrates are upregulated, including CDCrel-1, $\alpha$-synuclein, synphilin-1, Pael-R, $\beta$-tubulin, cyclin E, and synaptotagmin XI. These results confirm and extend previous observations in parkin exon 3 null mice in which CDCrel-1, $\alpha$-synuclein, and synphilin-1 were unaltered (Goldberg et al., 2003) and suggest that p38 may be an authentic parkin substrate. Consistent with the notion that p38 is an authentic parkin substrate, we found that p38 is upregulated in the brains of patients with parkin mutations. Similar to our observations in the exon 7 parkin knock-out mice, we failed to observe a significant upregulation of CDCrel-1, $\alpha$-synuclein, synphilin-1, Pael-R, $\beta$-tubulin, cyclin E, and synaptotagmin XI. This contrasts with previous reports, in which other investigators have found an upregulation of O-linked glycosylated $\alpha$-synuclein, cyclin E, and Pael-R (Imai et al., 2001; Shimura et al., 2001; Staropoli et al., 2003). Methodologic and/or regional brain differences could account for these disparities because we took special care to obtain age-matched and postmortemmatched control human brains for our comparison of substrate levels in AR-JP. Recent reports suggest a dual ubiquitin ligase function for parkin, lysine 48-linked proteasome-dependent and lysine 63-linked proteasome-independent ubiquitination of substrate (Doss-Pepe et al., 2005; Lim et al., 2005). One of the earliest reported substrates of parkin, synphilin-1, has been shown to be primarily ubiquitinated via K63-linkage, promoting the forma- 
tion of Lewy body-like inclusions (Lim et al., 2005). This phenomenon provides a reasonable explanation for the lack of accumulation of synphilin-1 in parkin null mice compared with wild type in our study and previously published reports (Goldberg et al., 2003). Thus, other reported substrates that have unchanged steady-state levels in parkin null mice and AR-JP brains may indeed be ubiquitinated by parkin but via the K63-ubiquitin linkage and therefore not targeted to the proteasome for degradation. Conversely, significant accumulation of p38 in the parkin null mice and AR-JP brains, as well as in cell culture with proteasome inhibitors, suggests a K48-linked proteasome-dependent ubiquitination by parkin. Additional analyses of the linkage-specific ubiquitination mediated by parkin may clarify the role of the known substrates in the pathogenesis of parkin-associated PD.

Recently, we reported that $S$-nitrosylation-mediated inhibition of parkin activity could be a potential link between the genetic and sporadic forms of PD (Chung et al., 2004). In brains from patients with PD and DLBD, there is a dramatic increase in the total level of $S$-nitrosylated proteins, including parkin (Chung et al., 2004). In PD and DLBD brains with enhanced $S$-nitrosylation, p38 also accumulates, providing another piece of evidence that the function of parkin is compromised by $S$-nitrosylation in vivo, thus linking genetic and sporadic forms of $\mathrm{PD}$ through the $S$-nitrosylation of parkin and the accumulation of p38. We also showed that p38 accumulates in Lewy bodies of PD patients, confirming a previous observation (Corti et al., 2003). These results together with the upregulation of p38 in parkin exon 7 knock-out mice, AR-JP brains, and PD and DLBD brains with $S$-nitrosylated parkin and the accumulation of p38 in Lewy bodies argue in favor of p38 being an authentic parkin substrate.

There is growing evidence that overexpression of a variety of parkin substrates may exert cytotoxicity and that overexpression of parkin protects against substrate toxicity (Imai et al., 2001; Dong et al., 2003; Ren et al., 2003; Staropoli et al., 2003). Indeed, parkin is thought to be a multipurpose neuroprotectant (Feany and Pallanck, 2003). We also observed that p38 has a toxic effect in cell culture and that parkin protects against toxicity induced by p38 itself and the enhancement of TNF $\alpha$ toxicity by p38, whereas the familial-associated parkin mutant $\mathrm{R} 42 \mathrm{P}$ fails to protects against p38 toxicity. Moreover, adenovirus-p38 overexpression in the SNc of mouse induced a significant loss of dopamine neurons.

The molecular mechanism by which p38 leads to cell death is not known. p38 is an important component of the multi-tRNA synthetase complex present in mammalian systems (Quevillon et al., 1999). p38-deficient mice revealed that this cofactor is a key scaffold for the assembly of the multi-tRNA synthetase complex (Kim et al., 2002). Because p38 is indispensable for the maintenance of the multi-ARS complex (Kim et al., 2002), the uncontrolled intracellular accumulation of p38 in parkin null mice and PD patients may alter the activity and the level of the multi-ARS complex and could lead to deleterious consequences, such as cellular dysfunction and ultimately cell death.

\section{References}

Ahn HC, Kim S, Lee BJ (2003) Solution structure and p43 binding of the p38 leucine zipper motif: coiled-coil interactions mediate the association between p38 and p43. FEBS Lett 542:119-124.

Bonifati V, Rizzu P, van Baren MJ, Schaap O, Breedveld GJ, Krieger E, Dekker MC, Squitieri F, Ibanez P, Joosse M, van Dongen JW, Vanacore N, van Swieten JC, Brice A, Meco G, van Duijn CM, Oostra BA, Heutink P (2003) Mutations in the DJ-1 gene associated with autosomal recessive early-onset parkinsonism. Science 299:256-259.
Choi P, Snyder H, Petrucelli L, Theisler C, Chong M, Zhang Y, Lim K, Chung KK, Kehoe K, D'Adamio L, Lee JM, Cochran E, Bowser R, Dawson TM, Wolozin B (2003) SEPT5_v2 is a parkin-binding protein. Brain Res Mol Brain Res 117:179-189.

Chung KK, Zhang Y, Lim KL, Tanaka Y, Huang H, Gao J, Ross CA, Dawson VL, Dawson TM (2001) Parkin ubiquitinates the alpha-synucleininteracting protein, synphilin-1: implications for Lewy-body formation in Parkinson disease. Nat Med 7:1144-1150.

Chung KK, Thomas B, Li X, Pletnikova O, Troncoso JC, Marsh L, Dawson VL, Dawson TM (2004) S-nitrosylation of parkin regulates ubiquitination and compromises parkin's protective function. Science 304:13281331.

Cookson MR (2003) Parkin's substrates and the pathways leading to neuronal damage. Neuromolecular Med 3:1-13.

Cookson MR (2005) The biochemistry of Parkinson's disease. Annu Rev Biochem, 74:29-52.

Corti O, Hampe C, Koutnikova H, Darios F, Jacquier S, Prigent A, Robinson JC, Pradier L, Ruberg M, Mirande M, Hirsch E, Rooney T, Fournier A, Brice A (2003) The p38 subunit of the aminoacyl-tRNA synthetase complex is a Parkin substrate: linking protein biosynthesis and neurodegeneration. Hum Mol Genet 12:1427-1437.

Cuervo AM (2004) Autophagy: in sickness and in health. Trends Cell Biol 14:70-77.

Dawson TM, Dawson VL (2003) Molecular pathways of neurodegeneration in Parkinson's disease. Science 302:819-822.

Dong Z, Ferger B, Paterna JC, Vogel D, Furler S, Osinde M, Feldon J, Bueler H (2003) Dopamine-dependent neurodegeneration in rats induced by viral vector-mediated overexpression of the parkin target protein, CDCrel-1. Proc Natl Acad Sci USA 100:12438-12443.

Doss-Pepe EW, Chen L, Madura K (2005) Alpha-synuclein and parkin contribute to the assembly of ubiquitin lysine63-linked multiubiquitin chains. J Biol Chem 280:16619-16624.

Feany MB, Pallanck LJ (2003) Parkin: a multipurpose neuroprotective agent? Neuron 38:13-16.

Goldberg MS, Fleming SM, Palacino JJ, Cepeda C, Lam HA, Bhatnagar A, Meloni EG, Wu N, Ackerson LC, Klapstein GJ, Gajendiran M, Roth BL, Chesselet MF, Maidment NT, Levine MS, Shen J (2003) Parkindeficient mice exhibit nigrostriatal deficits but not loss of dopaminergic neurons. J Biol Chem 278:43628-43635.

Huynh DP, Scoles DR, Nguyen D, Pulst SM (2003) The autosomal recessive juvenile Parkinson disease gene product, parkin, interacts with and ubiquitinates synaptotagmin XI. Hum Mol Genet 12:2587-2597.

Imai Y, Soda M, Inoue H, Hattori N, Mizuno Y, Takahashi R (2001) An unfolded putative transmembrane polypeptide, which can lead to endoplasmic reticulum stress, is a substrate of Parkin. Cell 105:891-902.

Imai Y, Soda M, Hatakeyama S, Akagi T, Hashikawa T, Nakayama KI, Takahashi R (2002) CHIP is associated with Parkin, a gene responsible for familial Parkinson's disease, and enhances its ubiquitin ligase activity. Mol Cell 10:55-67.

Itier JM, Ibanez P, Mena MA, Abbas N, Cohen-Salmon C, Bohme GA, Laville M, Pratt J, Corti O, Pradier L, Ret G, Joubert C, Periquet M, Araujo F, Negroni J, Casarejos MJ, Canals S, Solano R, Serrano A, Gallego E, et al. (2003) Parkin gene inactivation alters behaviour and dopamine neurotransmission in the mouse. Hum Mol Genet 12:2277-2291.

Jiang H, Jiang Q, Feng J (2004) Parkin increases dopamine uptake by enhancing the cell surface expression of dopamine transporter. J Biol Chem 279:54380-54386.

Kahle PJ, Haass C (2004) How does parkin ligate ubiquitin to Parkinson's disease? EMBO Rep 5:681-685.

Kim JY, Kang YS, Lee JW, Kim HJ, Ahn YH, Park H, Ko YG, Kim S (2002) p38 is essential for the assembly and stability of macromolecular tRNA synthetase complex: implications for its physiological significance. Proc Natl Acad Sci USA 99:7912-7916.

Kim MJ, Park BJ, Kang YS, Kim HJ, Park JH, Kang JW, Lee SW, Han JM, Lee HW, Kim S (2003) Downregulation of FUSE-binding protein and c-myc by tRNA synthetase cofactor p38 is required for lung cell differentiation. Nat Genet 34:330-336.

Kitada T, Asakawa S, Hattori N, Matsumine H, Yamamura Y, Minoshima S, Yokochi M, Mizuno Y, Shimizu N (1998) Mutations in the parkin gene cause autosomal recessive juvenile parkinsonism. Nature 392:605-608.

Lim KL, Chew KC, Tan JM, Wang C, Chung KK, Zhang Y, Tanaka Y, Smith W, Engelender S, Ross CA, Dawson VL, Dawson TM (2005) Parkin me- 
diates nonclassical, proteasomal-independent ubiquitination of synphilin-1: implications for Lewy body formation. J Neurosci 25:2002-2009.

Lucking CB, Durr A, Bonifati V, Vaughan J, De Michele G, Gasser T, Harhangi BS, Meco G, Denefle P, Wood NW, Agid Y, Brice A (2000) Association between early-onset Parkinson's disease and mutations in the parkin gene. French Parkinson's Disease Genetics Study Group. N Engl J Med 342:1560-1567.

Moore DJ, Zhang L, Troncoso J, Lee MK, Hattori N, Mizuno Y, Dawson TM, Dawson VL (2005) Association of DJ-1 and parkin mediated by pathogenic DJ-1 mutations and oxidative stress. Hum Mol Genet 14:71-84.

Paisan-Ruiz C, Jain S, Evans EW, Gilks WP, Simon J, van der Brug M, de Munain AL, Aparicio S, Gil AM, Khan N, Johnson J, Martinez JR, Nicholl D, Carrera IM, Pena AS, de Silva R, Lees A, Marti-Masso JF, Perez-Tur J, Wood NW, Singleton AB (2004) Cloning of the gene containing mutations that cause PARK8-linked Parkinson's disease. Neuron 44:595-600.

Palacino JJ, Sagi D, Goldberg MS, Krauss S, Motz C, Wacker M, Klose J, Shen J (2004) Mitochondrial dysfunction and oxidative damage in parkindeficient mice. J Biol Chem 279:18614-18622.

Paxinos G, Watson C, Pennisi M, Topple A (1985) Bregma, lambda and the interaural midpoint in stereotaxic surgery with rats of different sex, strain and weight. J Neurosci Methods 13:139-143.

Polymeropoulos MH, Lavedan C, Leroy E, Ide SE, Dehejia A, Dutra A, Pike B, Root H, Rubenstein J, Boyer R, Stenroos ES, Chandrasekharappa S, Athanassiadou A, Papapetropoulos T, Johnson WG, Lazzarini AM, Duvoisin RC, Di Iorio G, Golbe LI, Nussbaum RL (1997) Mutation in the alphasynuclein gene identified in families with Parkinson's disease. Science 276:2045-2047.

Quevillon S, Robinson JC, Berthonneau E, Siatecka M, Mirande M (1999) Macromolecular assemblage of aminoacyl-tRNA synthetases: identification of protein-protein interactions and characterization of a core protein. J Mol Biol 285:183-195.

Ren Y, Zhao J, Feng J (2003) Parkin binds to $\alpha / \beta$ tubulin and increases their ubiquitination and degradation. J Neurosci 23:3316-3324.

Sakata E, Yamaguchi Y, Kurimoto E, Kikuchi J, Yokoyama S, Yamada S, Kawahara H, Yokosawa H, Hattori N, Mizuno Y, Tanaka K, Kato K (2003) Parkin binds the Rpn10 subunit of 26 S proteasomes through its ubiquitin-like domain. EMBO Rep 4:301-306.

Shimura H, Hattori N, Kubo S, Mizuno Y, Asakawa S, Minoshima S, Shimizu N, Iwai K, Chiba T, Tanaka K, Suzuki T (2000) Familial Parkinson disease gene product, parkin, is a ubiquitin-protein ligase. Nat Genet 25:302-305
Shimura H, Schlossmacher MG, Hattori N, Frosch MP, Trockenbacher A, Schneider R, Mizuno Y, Kosik KS, Selkoe DJ (2001) Ubiquitination of a new form of alpha-synuclein by parkin from human brain: implications for Parkinson's disease. Science 293:263-269.

Staropoli JF, McDermott C, Martinat C, Schulman B, Demireva E, Abeliovich A (2003) Parkin is a component of an SCF-like ubiquitin ligase complex and protects postmitotic neurons from kainate excitotoxicity. Neuron 37:735-749.

Valente EM, Abou-Sleiman PM, Caputo V, Muqit MM, Harvey K, Gispert S, Ali Z, Del Turco D, Bentivoglio AR, Healy DG, Albanese A, Nussbaum R, Gonzalez-Maldonado R, Deller T, Salvi S, Cortelli P, Gilks WP, Latchman DS, Harvey RJ, Dallapiccola B, et al. (2004) Hereditary early-onset Parkinson's disease caused by mutations in PINK1. Science 304:1158-1160.

von Coelln R, Dawson VL, Dawson TM (2004a) Parkin-associated Parkinson's disease. Cell Tissue Res 318:175-184.

von Coelln R, Thomas B, Savitt JM, Lim KL, Sasaki M, Hess EJ, Dawson VL, Dawson TM (2004b) Loss of locus coeruleus neurons and reduced startle in parkin null mice. Proc Natl Acad Sci USA 101:10744-10749.

Yao D, Gu Z, Nakamura T, Shi ZQ, Ma Y, Gaston B, Palmer LA, Rockenstein EM, Zhang Z, Masliah E, Uehara T, Lipton SA (2004) Nitrosative stress linked to sporadic Parkinson's disease: $S$-nitrosylation of parkin regulates its E3 ubiquitin ligase activity. Proc Natl Acad Sci USA 101:10810-10814.

Yuan H, Sarre S, Ebinger G, Michotte Y (2005) Histological, behavioural and neurochemical evaluation of medial forebrain bundle and striatal 6-OHDA lesions as rat models of Parkinson's disease. J Neurosci Methods 144:35-45.

Zhang Y, Gao J, Chung KK, Huang H, Dawson VL, Dawson TM (2000) Parkin functions as an E2-dependent ubiquitin- protein ligase and promotes the degradation of the synaptic vesicle-associated protein, CDCrel-1. Proc Natl Acad Sci USA 97:13354-13359.

Zhao X, Ueba T, Christie BR, Barkho B, McConnell MJ, Nakashima K, Lein ES, Eadie BD, Willhoite AR, Muotri AR, Summers RG, Chun J, Lee KF, Gage FH (2003) Mice lacking methyl-CpG binding protein 1 have deficits in adult neurogenesis and hippocampal function. Proc Natl Acad Sci USA 100:6777-6782.

Zimprich A, Biskup S, Leitner P, Lichtner P, Farrer M, Lincoln S, Kachergus J, Hulihan M, Uitti RJ, Calne DB, Stoessl AJ, Pfeiffer RF, Patenge N, Carbajal IC, Vieregge P, Asmus F, Muller-Myhsok B, Dickson DW, Meitinger T, Strom TM, et al. (2004) Mutations in LRRK2 cause autosomaldominant parkinsonism with pleomorphic pathology. Neuron 44:601607. 